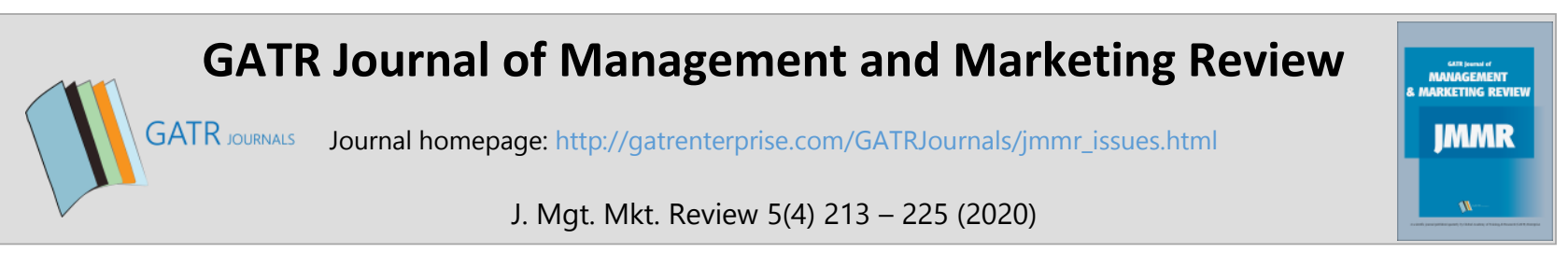

\title{
A New Theoretical Framework of Organizational Effectiveness from Knowledge and Ambidexterity Perspectives
}

\author{
Astadi Pangarso ${ }^{1 *}$, Endang Siti Astuti², Kusdi Raharjo ${ }^{3}$, Tri Wulida Afrianty ${ }^{4}$ \\ 1,2,3,4 Brawijaya University, Jl. MT. Haryono 163, 65145, Malang, Indonesia
}

\begin{abstract}
Objective - This paper aims to build a new theoretical framework related to organizational effectiveness. Unfortunately, there is no research which builds a theoretical framework of organizational effectiveness influenced by knowledge infrastructure capability, organizational environment, absorptive capacity and innovative ambidexterity.

Methodology/Technique - The theoretical framework is built from the past research of the organizational effectiveness antecedents using literature review method. The theoretical framework in this conceptual paper consists of nine propositions with three novelties: the direct relationship among knowledge infrastructure capability; absorptive capacity; and organizational environment to innovative ambidexterity.

Findings - This conceptual paper only applies structural contingency theory, knowledge-based theory and absorptive capacity theory in constructing relationships among concepts.

Novelty - This theoretical framework can be applied as a basis for the next future empirical research.

Type of Paper: Review

JEL Classification: L22, L23, M10.
\end{abstract}

Keywords: Knowledge Infrastructure Capability; Organizational Environment; Absorptive Capacity; Innovative Ambidexterity; Organizational Effectiveness.

Reference to this paper should be made as follows: Pangarso, A; Astuti, E.S; Raharjo, K; Afrianty, T.W. (2020). A New Theoretical Framework of Organizational Effectiveness from Knowledge and Ambidexterity Perspectives, J. Mgt. Mkt. Review, 5(4) 213 - 225. https://doi.org/10.35609/jmmr.2020.5.4(3)

\section{Introduction}

"An organization is a social entity that coordinated, and which continually works to fulfill shared goals" (Robbins, 1990) (Pangarso, 2014) (Pangarso, 2016). Fulfillment of organizational goals is closely related to organizational effectiveness. Organizational effectiveness is the part of organizational theory in the context of profit oriented and non-profit organizations (J. Bess and Dee, 2008). Organizational effectiveness is at the core of the theory of organization (Cameron, 2014). Management of organizational effectiveness plays an important role to be studied (Sayilar, 2016). The definition of organizational effectiveness is a construction based on the values and preferences of evaluators which are limited in order to be measured (Cameron, 2014).

\footnotetext{
* Paper Info: Revised: September 19, 2020

Accepted: December 31, 2020

* Corresponding author: Astadi Pangarso

E-mail: astadipangarso@student.ub.ac.id; astadipangarso@telkomuniversity.ac.id

Affiliation: Brawijaya University, J1. MT. Haryono 163, 65145, Malang, Indonesia
} 
According to several studies (Buller, 2012: Hatch, M. J., \& Cunliffe, 2013), it is stated that the effectiveness and organizational structure are two vital components in modern organizational theory. Organizational effectiveness is influenced by its contingency (Donaldson, 2001; Miles, 2012; Hatch, M. J, \& Cunliffe, 2013).

Effectiveness comes from the word effective having the meaning of "success" to achieve the goal. Specifically, it means the effectiveness of the organization which presents the success of the organization in achieving goals. The process of achieving these goals becomes a factor which is influential among the other factors such as knowledge of infrastructure capability, organizational environment, absorptive capacity and innovative ambidexterity.

Organizational effectiveness is directly influenced by the concept of knowledge infrastructure capability (Gold, Malhotra and Segars, 2001) and structural contingency theory (Miles, 2012; Hatch, MJ, \& Cunliffe, 2013) as knowledge infrastructure capability is a synthesis of three contingencies of organizational structure, organizational culture and technology. Knowledge infrastructure capability means the organizational ability to manage knowledge related to organizational structure, organizational culture and technology in order to actualize the organizational effectiveness. There is a research gap which does not support the concept of knowledge infrastructure capability in relation to organizational effectiveness, which is still insignificant in bridging between knowledge infrastructure capability and organizational effectiveness. Thus, it is essential to conduct empirical research which tests the relationship between knowledge infrastructure capability and organizational effectiveness (Chiu and Chen, 2016).

Organizational effectiveness is directly influenced by the organizational environment, in accordance with structural contingency theory (Donaldson, 2001; Miles, 2012; Hatch, M. J, \& Cunliffe, 2013). Organizational environment is a contingency organization affecting the effectiveness of the organization. There is an existing gap research which is inconsistent with the organizational environment and organizational effectiveness as it is proven by the research (García-Sánchez, García-Morales and Martín-Rojas, 2017) pointing out that the organizational environment negatively affects organizational effectiveness.

Organizational effectiveness is directly affecting the initial concept of absorptive capacity (Cohen and Levinthal, 1990; Miles, 2012). Absorptive capacity means that the organizational ability to obtain and interpret the knowledge is gained out of organizational environment to be further sorted out which is suitable to be further modified with existing knowledge and which is applied into the organization to be effective. There is a research gap which is inconsistent with the concept of the effect of absorptive capacity on organizational effectiveness. It is known that absorptive capacity has no positive and significant effect on organizational effectiveness (Ali, Seny Kan and Sarstedt, 2016).

Organizational effectiveness is directly influenced by innovative ambidexterity, in accordance with the concept of innovative ambidexterity leading to the concept of organizational ambidexterity (Tushman and O'Reilly, 1996) which states that organizational ambidexterity affects organizational effectiveness. Innovative ambidexterity is a more specific part of organizational ambidexterity from an innovation standpoint (Kortmann, 2011). Innovative ambidexterity also includes structural contingency theory and knowledge-based theory. Innovative ambidexterity means the company's ability to manage harmoniously between exploitation and exploration of knowledge in order to realize short-term efficiency and long-term innovation. There is a research gap which is inconsistent with the effect of innovative ambidexterity on organizational effectiveness. Research conducted by Ngo et al., (2017) states that innovative ambidexterity has no effect on organizational effectiveness.

It is hoped that this newly constructed theoretical framework can enrich the theory of modern organization as stated by Miles (2012) and by Hatch, MJ, \& Cunliffe (2013) which can develop structural contingency theory (Donaldson, 1996) (Donaldson, 2001) through the concept of organizational effectiveness (Kim S. Cameron, 1981). It is also influenced by knowledge of infrastructure capability (Gold, Malhotra and Segars, 2001), organizational environment (Donaldson, 2001), absorptive capacity (Cohen and Levinthal, 1990) and 
organizational ambidexterity (Tushman and O'Reilly, 1996) (Kortmann, 2011). This research studies the business organization section in general.

\section{Literature Review}

\subsection{Organizational effectiveness}

The definition of effectiveness according to Daft is the degree to which an organization realizes its goals (J. L. Bess and Dee, 2008). From the various dimensions of organizational effectiveness of various researchers (Budhiraja and Malhotra, 2013) it can be assumed that the word effectiveness can be equated from performance, productivity, financial gain. In addition, effectiveness has the same meaning with performance in a narrower scope (Volberda et al., 2012).

Organizational effectiveness is an outcome of structural contingency theory. Structural contingency theory states that in order for an organization to be effective it is influenced by the suitability between organizational design / organizational structure and its contingency (J. Bess and Dee, 2008; Miles, 2012; Gay and Vikkelsø, 2017). Contingency has something in common with the situation or context (Donaldson, 1996). The key word in this theory is the fitness or suitability (McEvily, Soda and Tortoriello, 2014) which means that the more the structure of the organization can adapt to its contingencies, the more effective the organization will be (Fenton and Pettigrew, 2000).

According to various contingency researchers, the organization consists several aspects of: external environment, structure, culture, capability, resources, organizational goals (Kim S. Cameron, 1981) (Ruchi Srivastava \& Vinayshil Gautam, 2009); technology, the external environment of culture, technology and organizational structure (Donaldson, 2008); environment, technology and strategy (Oliveira, 2012); technology, structure and culture (Volberda et al., 2012); strategy, size, technology; environment (Pfeffer, 1997) (Sayilar, 2016); environment, technology, size (Clegg, Kornberger and Pitsis, 2016).

Contingency theory is a theory which is widely used in research related to organizational science, which can provide solutions to problems related to organizational design (Meilich, 2006); as well as an important part of organizational scholarship (Farazmand, 2002) (Trautmann, 2008). For applications related to organizational problem solutions, contingency theory plays a role specifically for internal organizational coordination issues (Donaldson, 2008). Contingency theory is a middle-range theory which discusses the identification and adjustment of context in relation to organizational governance (Volberda et al., 2012). Contingency theory is an organizational effort to adapt to its environment (Burton, 1998).

The organizational theorist from Australia Lex Donaldson in 1996 on the theory of structural contingency states that: "There are several contingency factors (multi contingencies) such as: strategy, size, task uncertainty and technology. These are characteristics of the organization. However, these organizational characteristics reflect the influence of the environment in which the organization is located. Thus, in order to be effective, the organization needs to fit its structure to the contingency factors of the organization and the environment. Hence, the organization is seen as adapting to its environment."

The mention of structural contingency theory was expressed by Pfeffer in 1982 (Donaldson, 2001). The theory of structural contingency according to the positivist paradigm is an established theory of position in organizational scholarship (Donaldson, 1996). Structural contingency theory has the basic assumption that there is not only one way of organizing an organization, but the way in organizing organizations has also different effects (Pfeffer, 1997) (Peh and Low, 2013) (Koskinen, 2013). Environmental change conditions will tend to have a specific design on their respective organizational structures which further result in increased effectiveness (Bøllingtoft et al., 2009; Kortmann, 2011).

\subsection{Organizational environment}

The organizational environment is part of the structural contingency theory. The first British organization experts Tom Burns and George M. Stalker in 1961 stated that the organizational structure is influenced by the 
environmental characteristics of the organization. Organizational environment is a concept affecting the design (structure) and organizational effectiveness. From the framework of the organizational environment, it can be seen that the organizational structure is the antecedent and the effectiveness is an outcome (Meinhardt, Junge, \& Weiss, 2018).

The relationship between organizational environmental contingencies to organizational effectiveness in structural contingency theory is included in functional aspects (Donaldson, 1996). Environmental uncertainty (environmental dynamics) becomes the most widely researched concepts of contingency theory (Meilich, 2006). The research (Volberda et al., 2012) related to structural contingency theory covers the concept of organizational environment, environmental turbulence consisting of hyper competition, market dynamism and speed of industry movement. The organizational environmental dimension under this study is the environmental dynamics (Meinhardt, Junge and Weiss, 2018).

\subsection{Knowledge infrastructure capability}

The concept of knowledge infrastructure capability begins with the concept of organizational capability which later decreases to knowledge management capability (Pandey et al., 2016) and knowledge management capability comprises of knowledge infrastructure and knowledge process capability (Pandey and Dutta, 2013). The reason of discussing the knowledge of infrastructure capability in this study is driven by a synthesis of existing concepts in structural contingency theory consisting of structure, culture and technology (Keshavarz, Esmaili Givi and Shekari, 2018).

Knowledge infrastructure capability is an organizational ability to manage the structure, culture and technology related to knowledge affecting the effectiveness of the organization. This concept was first stated by Gold, Malhotra and Segars (2001). This concept begins with the idea that in order to survive, the organization must be able to manage the important resource which is the knowledge. Therefore, the knowledge of capability awareness also relates to a knowledge-based theory proposed by Grant (1996) and Zack (1999) emphasizing that organizations need coordination and integration to be learned by members of the organization (Miles, 2012). This theory suggests that knowledge management (search, use, storage, development, capacity and capability) contributes to the survival, growth and success of an organization.

Knowledge itself is classified into four things such as: declarative ("what"); procedural ("how); determination ("when") and wisdom ("why"). Several things which are discussed in this theory include tacit knowledge (knowledge which exists within a person) and explicit knowledge (general knowledge). As stated by Dalkir (2011), an organization is said to be effective if the organization succeeds in discovering, absorbing and exploiting knowledge both within the organization and from the external environment.

This theory assumes that each heterogeneous organization in the use of knowledge in generating outcomes plays as an important resource. The research related to knowledge-based theory discusses the exploitation of organizational capability; the creation of new knowledge, capabilities; the knowledge exchange process and intellectual capital (structure, human, and relations).

\subsection{Absorptive capacity}

Absorptive capacity is the theory proposed by several researchers (Cohen and Levinthal, 1990; Miles, 2012; Mariano and Walter, 2015) and is defined as "the firm's ability to recognize value, incorporate and exploit new exogenous ideas" (Nowak, 2017) or the ability of an organization to recognize the value of new information from outside, which mixes it up and is applied to important things directly related to innovation. This theory states the importance of absorbing knowledge from the outside organization in order to be flexible and innovative to improve performance (Miles, 2012). Therefore, it is apparent that the importance of organizational ability to absorb external knowledge to create innovation is essential (Child, 2015), where innovation is related to effectiveness and competitiveness. Knowledge-based organizations have the ability to absorb knowledge. 
There are four dimensions of absorptive capacity: acquisition and assimilation (called as PACAP: potential absorptive capacity); transformation and exploitation (called as RACAP: realized absorptive capacity). PACAP is concerned with how organizations acquire and learn new knowledge gained from the outside organization, whereas RACAP is linked to the introduction of new knowledge from PACAP to further incorporated funds modified with existing knowledge in the organization for subsequent implementation (Miles, 2012).

Based on research conducted by Apriliyanti and Alon (2017), it is stated that the topic of absorptive capacity research becomes a very interesting topic to be studied which can be seen from the increasing trend from 1990 to 2015 reaching nearly 3500 numbers of publications related to this topic. In addition, current topics related to absorptive capacity become the top ten research topics in 2015 (Mariano and Walter, 2015).

\subsection{Innovative ambidexterity}

The innovative ambidexterity concept is part of the organizational ambidexterity concept. Organizational ambidexterity is still not found to be a consistent theoretical framework (Simsek, 2009). Furthermore, another study supporting the previous statement is that the concept of organizational ambidexterity which is theoretically still not consistently formed; thus, opening the gap for further research (Kortmann, 2011). If the organizational ambidexterity of a larger scope of innovative ambidexterity is still not consistent with the theoretical framework, then this is also the case for innovative ambidexterity. Innovative ambidexterity means the ability to simultaneously pursue both incremental and discontinuous (exploratory) innovation. Innovative ambidexterity occurs in situations where paradoxical activity occurs simultaneously within an organization.

Organizational ambidexterity affects organizational effectiveness (Kortmann, 2011) and business performance (Mashahadi, Ahmad and Mohamad, 2016). Organizational ambidexterity is influenced by the environment and organizational structure (Simsek, 2009) (Asif, 2017). Then the concept of organizational ambidexterity and innovative ambidexterity is also related to the theory of structural contingency.

\subsection{Theoretical relationship to the concepts of research}

The concept of organizational effectiveness is part of the structural contingency theory; that the organization's effectiveness becomes the output of the structural contingency theory. The concept of knowledge infrastructure capability includes structural contingency theory and knowledge-based theory. The organizational structure, organizational culture and technology, which are considered as parts of knowledge infrastructure capability are also a contingency within the structural contingency theory. Knowledge infrastructure capability also includes knowledge-based theory because it has an understanding to manage organizational structure, organizational culture and specific technology related to knowledge. Hence, knowledge in an organization plays an important role for the effectiveness of an organization in order to be managed properly.

The concept of an organizational environment is a structural contingency theory. The concept of absorptive capacity is also a theory which states that in order to excel effectively an organization must have the ability to identify and to absorb knowledge from outside to further be adjusted, modified and applied.

The concept of innovative ambidexterity includes structural contingency theory because it affects organizational effectiveness, which becomes the output of the structural contingency theory. The concept of innovative ambidexterity also includes knowledge-based theory due to its short-term efficiency and longterm innovation being necessary to manage the exploitation of existing knowledge within the organization and the exploration of knowledge gained from the outside environment harmoniously.

\subsection{The framework of research proposition}

The research proposition framework in this study is a combination of various relationships between research concepts. The dependent concept of this research is the concept of organizational effectiveness, 
which is based on previous studies such as knowledge infrastructure capability, organizational environment, absorptive capacity and innovative ambidexterity. From the previous studies, it can be seen that there is a relationship among the five concepts.

The impact of knowledge infrastructure capability on organizational effectiveness is based on previous studies (Cho and Korte, 2014; Bagheri, Hamidizadeh and Sabbagh, 2015; Bharadwaj, Chauhan and Raman 2015; Chiu and Chen, 2016 and Shih and Tsai, 2016). The influence of knowledge infrastructure capability on absorptive capacity is based on research conducted by Cohen and Levinthal (1990). The influence of organizational environment on organizational effectiveness is based on previous studies conducted by Jantz (2015); Bustinza et al., (2016); Prajogo (2016); Majid (2016); García-Sánchez, García-Morales and MartínRojas (2017); and by Akgün, Keskin and Kırçovalı (2017). The influence of organizational environment with absorptive capacity is based on a study conducted by Roberts (2015). The effect of absorptive capacity for organizational effectiveness is based on previous studies (Ali, Seny Kan and Sarstedt, 2016; Mardi et al., 2016; Kesk and Ayar, 2017; García-Sánchez, García-Morales and Martín-Rojas, 2017; and Rangus and Slavec, 2017). The influence of innovative ambidexterity on organizational effectiveness is based on former studies (Lin et al., 2013; Jantz, 2015; Mardi et al., 2016; Dunlap et al., 2016; Ngo et al., 2017; Lee and Garrett, 2017; Zang and Li, 2017; and Vrontis et al., 2016).

Based on the future research of previous studies (Bagheri, Hamidizadeh and Sabbagh, 2015; Duchek, 2015; Roberts, 2015; Rangus and Slavec, 2017), it points out that there is the need for empirical research to examine the effect of knowledge infrastructure capability on absorptive capacity because there is still a relationship of inconsistent influence of knowledge infrastructure capability with absorptive capacity.

P1: Knowledge infrastructure capability has a positive effect on absorptive capacity

The relationship between knowledge infrastructure capability and innovative ambidexterity has not yet been found between the two concepts. This is also reinforced by the assumption that if the organization has good knowledge of infrastructure capability, then the ability of the organization is proven to be more innovative through increasing exploitation and exploration.

P2: Knowledge of infrastructure capability has a positive effect on innovative ambidexterity

Research conducted by Chiu and Chen (2016) states that the knowledge infrastructure capability has no significant effect on organizational effectiveness. This is not in line with structural contingency theory which states that organizational structure, organizational culture and technology affect organizational effectiveness. If the ability of an organization to manage properly and sustainable is higher, so the organizational structure, organizational culture and knowledge-related technology can be more effective for the organization. This is supported by several studies (Bharadwaj, Chauhan and Raman, 2015 and Cho and Korte, 2014) which prove that there is a direct and significant relationship of knowledge infrastructure capability to organizational effectiveness. The second research conducted by Shih and Tsai (2016) states that the knowledge infrastructure capability has a positive and indirectly significant effect on organizational effectiveness. Other research (Bagheri, Hamidizadeh and Sabbagh, 2015) states that the knowledge of indirect infrastructure capability (the concept of mediator such as knowledge process capability and creative learner organization) has an effect on company performance.

P3: knowledge of infrastructure capability has a positive effect on organizational effectiveness

Research (Roberts, 2015) (Ali et al., 2017) suggests for future studies that there is the need for empirical research on organizational environmental relationships to absorptive capacity. A logical explanation for the relationship is because the organization absorbs knowledge from the external environment, then the environmental conditions of the organization will affect the knowledge absorbed by the organization.

P4: The organizational environment has a positive effect on absorptive capacity

There is no research which examines the direct relationship between organizational environments to innovative ambidexterity. This influence relationship is also influenced by the logical assumption that in order to balance exploitation and exploration related to organizational innovation, environmental conditions also have an effect as the innovation is also influenced by environmental conditions. Organizations will be 
increasingly good at innovating if the organization can manage the response to its organizational environment.

P5: The organizational environment has a positive effect on innovative ambidexterity

The study about the relationship between organizational environments and organizational effectiveness has been conducted. Research conducted by Jantz (2015) states that the organizational environment has no significant effect on organizational effectiveness. Research conducted by García-Sánchez, García-Morales and Martín-Rojas (2017) state that the organizational environment indirectly has a positive and significant effect on organizational effectiveness. Another study by Prajogo (2016) suggests that the organizational environment does not fully influence moderating relationships between innovation and organizational effectiveness. Research (Kamasak, Yavuz and Altavas, 2016) explains that part of the organizational environment partially moderates the relationship between knowledge management capability and organizational effectiveness. However, the relationship between the concepts of this study still provides gaps in research related to the significant relationship either directly or indirectly between the organizational environment and organizational effectiveness.

P6: The organizational environment has a positive effect organizational effectiveness

Research conducted by Mardi et al. (2016) and Pangarso et.al. (2020a; 2020b) states that there is a positive and significant influence of absorptive capacity on organizational ambidexterity. However, research on the effect of absorptive capacity on innovative ambidexterity has not been conducted empirical. This opens up an important research gap to be studied as a novelty. The better the organization's ability to absorb, assimilate, transform and apply knowledge from the environment, the cleverer the organization can be to exploit and explore innovation.

P7: Absorptive capacity has a positive effect on innovative ambidexterity

A previous study, which discussed the relationship between absorptive capacity and organizational performance through the mediation of product innovation concepts, as conducted by Kesk and Ayar (2017) finds a positive and significant relationship. This finding is also in accordance with another study conducted by Rangus and Slavec (2017). Several other studies conducted by Ali, Seny Kan and Sarstedt (2016) state that there is a partially positive indirect effect to absorptive capacity on organizational effectiveness. There are inconsistencies in the results of the three studies.

P8: Absorptive capacity has a positive effect organizational effectiveness

Previous research conducted by Popadic, Pucko and Cerne (2016) states that innovative ambidexterity has an effect on company performance. Another study (Suzuki, 2015) also states that there are two dimensions between exploitative ambidexterity and explorative ambidexterity which have balanced and combined relationship. These two mechanisms are proven to have a positive effect on the performance of the company. Further, another research conducted by Mashahadi, Ahmad and Mohamad (2016) also finds the same effect between innovative ambidexterity on the performance of small and medium enterprises. Other research, conducted by Zang and $\mathrm{Li}$, (2017) identifies a positive and significant result between innovative ambidexterity on organizational performance. The same result is stated by Jantz (2015) and Mardi et al., (2016) in which organizational ambidexterity positively and significantly influences organizational effectiveness. However, other research (Lee, Lee and Garrett, 2017) states that organizational ambidexterity (through innovation) has not positively and significantly affect the effectiveness of the organization. Similarly, Ngo et al. (2017) finds no significant influence between innovative ambidexterity on firm performance.

P9: Innovative ambidexterity has a positive effect on organizational effectiveness

\section{Research Methodology}

This research is a conceptual study using the literature review method. The data needed by this research is secondary data in the form of scientific articles published in journals and academic books. The secondary data of this study were dominated by English documents. Secondary data were sought based on topics related 
to antecedents of organizational effectiveness. Secondary data searches use the google search engine and various search engines specifically for scientific document databases such as Scopus, research gate, $\mathrm{j}$-storing, using campus scientific document database facilities and others. After being collected, the secondary data is filtered in two stages, namely the first stage by checking the title and abstract, if there is something that does not match the antecedents of organizational effectiveness, the document is not included to be discussed in this study. The second stage after finding a suitable scientific document is to read each document carefully to examine in more detail the antecedents of organizational effectiveness. After the second stage is completed, scientific documents are collected as material for compiling the influence proposition between the antecedents of organizational effectiveness constructs to form a theoretical framework.

\section{Results and Discussion}

Based on the combination of influence between the concepts of previous research above, a framework of research proposition is prepared by the researchers of this study. The ability of an organization to simultaneously exploit existing knowledge, for short-term efficiency and explore outside knowledge for long-term innovation is influenced by: (1) organizational ability to manage knowledge through organizational structure, organizational culture and technology; (2) the external environment of the organization; and (3) the organization's ability to identify and absorb external knowledge to be further adapted and applied into the organization. The research proposition framework is formed from a literature review that results in a research gap (Schwab, 2005). This research proposition framework has the meaning (ontology) which is able to meet organizational effectiveness where there is a sequence of process relationship between concepts as follows.

Organizational effectiveness can be achieved by ambidexterity to exploit and explore knowledge which is influenced by the organization's ability to absorb (recognize, blend and use) knowledge from the outside environment (dynamic organizational environment and there is competition within it) and organizational ability to manage knowledge infrastructure. The research proposition framework has six relations of influence and possible novelty which has not been studied such as: the relationship of influence between the knowledge infrastructure capability to innovative ambidexterity, organizational environment to innovative ambidexterity and absorptive capacity to innovative ambidexterity. The proposition of this study includes a directional proposition which predicts the proposition of the outcome (Newhart and Patten, 2018). This proposition is based on the premise of prior studies which are appropriate and supportive to the theory of structural contingency as the main theory. A theoretical framework with novelty is presented in the following figure 1 .

Black lines : The path which has been studied

Yellow lines : Novelty path

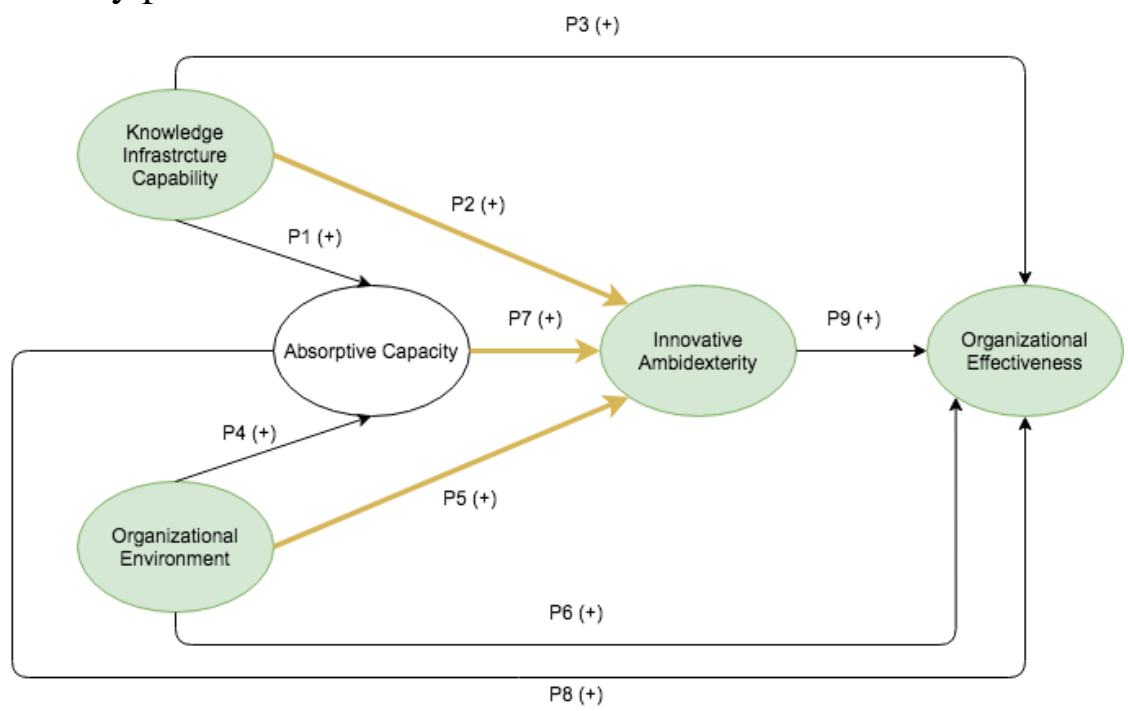

Figure 1. Theoretical Framework 


\section{Conclusion}

The implications of this research are theoretical implications. This research has implications for completing the discussion of the theory of structural contingency, knowledge-based theory and absorptive capacity theory in a theoretical framework. These three theories are theories related to antecedents of organizational effectiveness. So far based on this literature review, there has never been a study that has compiled a theoretical framework for organizational effectiveness antecedents consisting of the constructs: knowledge infrastructure capability, organizational environment, absorptive capacity and innovative ambidexterity.

This study produces a theoretical framework proposal related to antecedents of organizational effectiveness. This theoretical framework serves as a basis for quantitative empirical testing for future research related to antecedents of organizational effectiveness. The theoretical framework with the research proposition in this conceptual paper is only based solely on the theory of structural contingency, knowledge-based theory and absorptive capacity theory perspectives. It is possible to develop a theoretical framework linked to the future research agenda to supplement the fund or replace the underlying theories.

\section{Acknowledgement}

Author would like to acknowledge LPDP as a research funder and LPPM Telkom University as a publication incentive funder.

\section{References}

Akgün, A. E., Keskin, H., \& Kırçoval1, S. Y. (2019). Organizational wisdom practices and firm product innovation. Review of Managerial Science, 13(1), 57-91.doi: 10.1007/s11846-017-0243-2.

Ali, M., Ali, I., Al-Maimani, K. A., \& Park, K. (2018). The effect of organizational structure on absorptive capacity in single and dual learning modes. Journal of Innovation \& Knowledge, 3(3), 108-114. doi: https://doi.org/10.1016/j.jik.2017.03.007.

Ali, M., Seny Kan, K. A. and Sarstedt, M. (2016) 'Direct and configurational paths of absorptive capacity and organizational innovation to successful organizational performance', Journal of Business Research. Elsevier Inc., 69(11), pp. 5317-5323. doi: 10.1016/j.jbusres.2016.04.131.

Apriliyanti, I. D., \& Alon, I. (2017). Bibliometric analysis of absorptive capacity. International Business Review, 26(5), 896-907.doi: 10.1016/j.ibusrev.2017.02.007.

Asif, M. (2017). Exploring the antecedents of ambidexterity: a taxonomic approach. Management Decision. doi: 10.1108/MD-12-2016-0895.

Bagheri, R., Hamidizadeh, M. R., \& Sabbagh, P. (2015). The mediator role of KM process for creative organizational learning case study. Vine.doi: http://dx.doi.org/10.1108/02683940010305270.

Bess, J. L., \& Dee, J. R. (2008). Understanding college and university organization: Dynamics of the system (Vol. 2). Stylus Publishing, LLC.

Bess, J. L. and Dee, J. R. (2008) Understanding College and University Organization: Dynamics of the system Volume II-Dynamics of the System. Stylus Publishing. Available at: http://books.google.com/books?id=tZMzH9ALvtsC\&pgis=1.

Bharadwaj, S. S., Chauhan, S., \& Raman, A. (2015). Impact of knowledge management capabilities on knowledge management effectiveness in Indian organizations. Vikalpa, 40(4), 421-434. doi: 10.1177/0256090915613572.

Birkinshaw, J., \& Gupta, K. (2013). Clarifying the distinctive contribution of ambidexterity to the field of organization studies. Academy of Management Perspectives, 27(4), 287-298.doi: 10.5465/amp.2012.0167.

Blarr, W. H. (2012). Organizational ambidexterity: Implications for the strategy-performance linkage. Springer Science \& Business Media. doi: 10.1007/978-3-8349-6859-3. 
Håkonsson, D. D., Nielsen, J. F., Snow, C. C., \& Ulhøi, J. (Eds.). (2009). New Approaches to Organization Design: Theory and Practice of Adaptive Enterprises (Vol. 8). Springer Science \& Business Media.

Budhiraja, S., \& Malhotra, M. (2013). Leadership style \& organizational effectiveness in Indian it \& banking industry. The Indian Journal of Industrial Relations, 270-285.

Burton, R. M., Obel, B., Hunter, S., Søndergaard, M., \& Døjbak, D. (1998). Strategic organizational diagnosis and design: Developing theory for application. Springer Science \& Business Media. doi: 10.1007/978-1-4684-0021-2.

Khan, Z., Rao-Nicholson, R., Akhtar, P., Tarba, S. Y., Ahammad, M. F., \& Vorley, T. (2019). The role of HR practices in developing employee resilience: A case study from the Pakistani telecommunications sector. The International Journal of Human Resource Management, 30(8), 1342-1369.doi: 10.1080/09585192.2016.1216878.

Vodosek, M., \& den Hartog, D. (2014). Wiley Encyclopedia of Management. https://doi.org/10.1002/9781118785317.weom110202

Child, J. (2015). Organization: contemporary principles and practice. John Wiley \& Sons.doi: 10.1002/9781119176862. Chiu, C. N., \& Chen, H. H. (2016). The study of knowledge management capability and organizational effectiveness in Taiwanese public utility: the mediator role of organizational commitment. SpringerPlus, 5(1), 1520.doi: 10.1186/s40064-016-3173-6.

Cho, T., \& Korte, R. (2014). Managing knowledge performance: testing the components of a knowledge management system on organizational performance. Asia Pacific Education Review, 15(2), 313-327.doi: 10.1007/s12564-014-9333$\mathrm{x}$.

Clegg, S. R., Kornberger, M., \& Pitsis, T. (2015). Managing and organizations: An introduction to theory and practice. Sage. https://doi.org/10.1080/14767333.2017.1358685

Cohen, W. M., \& Levinthal, D. A. (1990). Absorptive capacity: A new perspective on learning and innovation. Administrative science quarterly, 128-152. https://doi.org/10.2307/2393553

Dalkir, K. (2017). Knowledge management in theory and practice. MIT press. doi: 10.1212/01.CON.0000453321.98131.cc.

Donaldson, L. (1996). For positivist organization theory. Sage.doi: 10.2307/2393625.

Donaldson, L. (2006). The contingency theory of organizational design: challenges and opportunities. In Organization design (pp. 19-40). Springer, Boston, MA. doi: http://sci-hub.tw/10.1007/0-387-34173-0_2.

Donaldson, L. (2008) Designing Organizations 21st Century Approaches. doi: 10.1007/s13398-014-0173-7.2.

Duchek, S. (2015). Enhancing absorptive capacity for innovation and change: The role of structural determinants. Journal of Change Management, 15(2), 142-160. doi: 10.1080/14697017.2014.988637.

Dunlap, D., Parente, R., Geleilate, J. M., \& Marion, T. J. (2016). Organizing for innovation ambidexterity in emerging markets: taking advantage of supplier involvement and foreignness. Journal of Leadership \& Organizational Studies, 23(2), 175-190.doi: 10.1177/1548051816636621.

Farazmand, A. (Ed.). (2002). Modern organizations: Theory and practice. Greenwood Publishing Group. doi: $10.2307 / 2391475$.

Pettigrew, A. M., \& Fenton, E. M. (Eds.). (2000). The innovating organization. Sage.doi: 10.1007/BF03180796.

García-Sánchez, E., García-Morales, V. J., \& Martín-Rojas, R. (2018). Analysis of the influence of the environment, stakeholder integration capability, absorptive capacity, and technological skills on organizational performance through corporate entrepreneurship. International Entrepreneurship and Management Journal, 14(2), 345-377. doi: 10.1007/s11365-017-0436-9.

Du Gay, P., \& Vikkelsø, S. (2016). For formal organization: The past in the present and future of organization theory. Oxford University Press.

Gold, A. H., \& Malhotra, A. and Segars, AH (2001). Knowledge management: An organizational-capabilities. https://doi.org/10.1080/07421222.2001.11045669

Grant, R. M. (1996). Toward a knowledge-based theory of the firm. Strategic management journal, 17(S2), $109-122$. https://doi.org/10.1002/smj.4250171110

Hatch, M. J. (2019). Organization Theory: Modern, Symbolic, and Postmodern Perspectives. South Asian Journal of Management, 26(4), 215-218.

O'Reilly III, C. A., \& Tushman, M. L. (2013). Organizational ambidexterity: Past, present, and future. Academy of management Perspectives, 27(4), 324-338.doi: 10.5465/amp.2013.0025.

Jantz, R. C. (2015). The determinants of organizational innovation: An interpretation and implications for research libraries. College \& Research Libraries, 76(4), 512-536.doi: 10.5860/crl.76.4.512. 
Junni, P. et al. (2013) 'Organizational Ambiexterity and Performance: A Meta-Analysis', The Academy of Management Perspective, 27(4), pp. 299-312. doi: 10.5465/amp.2012.0015.

Kamasak, R., Yavuz, M., \& Altuntas, G. (2016). Is the relationship between innovation performance and knowledge management contingent on environmental dynamism and learning capability? Evidence from a turbulent market. Business Research, 9(2), 229-253.doi: 10.1007/s40685-016-0032-9.

Kamasak, R., Yozgat, U., \& Yavuz, M. (2017). Knowledge process capabilities and innovation: Testing the moderating effects of environmental dynamism and strategic flexibility. Knowledge Management Research \& Practice, 15(3), 356368.doi: 10.1057/s41275-017-0068-4.

Keshavarz, H., Givi, M. R. E., \& Shekari, M. R. (2018). Knowledge management infrastructures and organizational intelligence in Iranian research centers. Data Technologies and Applications.doi: 10.1108/DTA-12-2016-0080.

Kesk, H. and Ayar, H. (2017) 'Dynamic Rules of Action, Market Knowledge Absorptive Capacity and Firm Innovativeness: An Empirical Analysis', Dogus University Journal, 18(1), pp. 115-134.

Kim S. Cameron (1981) 'Domains of Organizational Effectiveness in Colleges and Universities', The Academy of Management Journal, 24(1), pp. 25-47. Available at: http://www.jstor.org/stable/255822.

Kortmann, S. (2012). The relationship between organizational structure and organizational ambidexterity: A comparison between manufacturing and service firms. Springer Science \& Business Media.doi: 10.1007/978-3-83493630-1.

Koskinen, K. U. (2013). Knowledge production in organizations. Switzerland: Springer International Publishing.doi: 10.1007/978-3-319-00104-3.

Lee, R., Lee, J. H., \& Garrett, T. C. (2019). Synergy effects of innovation on firm performance. Journal of Business Research, 99, 507-515. doi: 10.1016/j.jbusres.2017.08.032.

Lin, H. E., McDonough III, E. F., Lin, S. J., \& Lin, C. Y. Y. (2013). Managing the exploitation/exploration paradox: The role of a learning capability and innovation ambidexterity. Journal of Product Innovation Management, 30(2), 262278.doi: 10.1111/j.1540-5885.2012.00998.x.

Majid, Z. Y. A. World Journal of Entrepreneurship, Management and Sustainable Development.doi: http://dx.doi.org/10.1108/WJEMSD-03-2016-0015.

Mardi, M., Arief, M., Furinto, A., \& Kumaradjaja, R. (2018). Sustaining organizational performance through organizational ambidexterity by adapting social technology. Journal of the Knowledge Economy, 9(3), 1049-1066. doi: 10.1007/s13132-016-0385-5.

Mariano, S., \& Walter, C. (2015). The construct of absorptive capacity in knowledge management and intellectual capital research: content and text analyses. Journal of Knowledge Management.doi: 10.1108/JKM-08-2014-0342.

Mashahadi, F., Ahmad, N. H., \& Mohamad, O. World Journal of Entrepreneurship, Management and Sustainable Development. doi: 10.1108/WJEMSD-09-2015-0036.

McEvily, B., Soda, G., \& Tortoriello, M. (2014). More formally: Rediscovering the missing link between formal organization and informal social structure. Academy of Management Annals, 8(1), 299-345.doi: 10.1080/19416520.2014.885252.

Meilich, O. (2006). Bivariate models of fit in contingency theory: Critique and a polynomial regression alternative. Organizational research methods, 9(2), 161-193. doi: 10.1177/1094428105284915.

Meinhardt, R., Junge, S., \& Weiss, M. (2018). The organizational environment with its measures, antecedents, and consequences: a review and research agenda. Management Review Quarterly, 68(2), 195-235.

https://doi.org/10.1007/s11301-018-0137-7

Miles, J. A. (2012). Management and organization theory: A Jossey-Bass reader (Vol. 9). John Wiley \& Sons.

Patten, M. L., \& Newhart, M. (2017). Understanding research methods: An overview of the essentials. Taylor \& Francis.https://doi.org/10.1080/00949655.2019.1628904

Ngo, L. V., Bucic, T., Sinha, A., \& Lu, V. N. (2019). Effective sense-and-respond strategies: Mediating roles of exploratory and exploitative innovation. Journal of Business Research, 94, 154-161. doi: 10.1016/j.jbusres.2017.10.050.

Nowak, R. (2017). Demystifying absorptive capacity: Focus on firm size and employee empowerment. International Journal of Innovation Management, 21(06), 1750050. doi: 10.1142/S1363919617500505.

Oliveira, N. (2011). Automated organizations: Development and structure of the modern business firm. Springer Science \& Business Media. doi: 10.1007/978-3-7908-2759-0.

Pandey, S. C. (2016). Organizational Capabilities and Knowledge Management Success: Evidences from Two MidSized Indian IT Companies. International Journal of Asian Business and Information Management (IJABIM), 7(1), 18 29.doi: 10.4018/IJABIM.2016010102. 
Pandey, S. C., \& Dutta, A. (2013). Role of knowledge infrastructure capabilities in knowledge management. Journal of knowledge management. doi: 10.1108/JKM-11-2012-0365.

Pangarso, A. (2014, August). Organization's structure based on competing value approach and merger strategy. In 2014 2nd International Conference on Technology, Informatics, Management, Engineering \& Environment (pp. 189-193). IEEE. doi: 10.1109/time-e.2014.7011616.

Pangarso, A. (2016). Lecturer Sociometric Badge as Digital Platform in Indonesia Higher Education Institutions from Organizational Effectiveness Perspective. Advanced Science Letters, 22(12), 4308-4311.doi: 10.1166/asl.2016.8134.

Pangarso, A., Astuti, E. S., Raharjo, K., \& Afrianty, T. W. (2020). Data of innovation ambidexterity as a mediator in the absorptive capacity effect on sustainable competitive advantage. Data in brief, 29, 105200. https://doi.org/10.1016/j.dib.2020.105200.

Pangarso, A., Astuti, E. S., Raharjo, K., \& Afrianty, T. W. (2020). The impact of absorptive capacity and innovation ambidexterity on sustainable competitive advantage: the case of Indonesian higher education. Entrepreneurship and Sustainability Issues, 7(3), 2436.http://doi.org/10.9770/jesi.2020.7.3(65)

Peh, L. C., \& Low, S. P. (2013). Organization design for international construction business. Springer Science \& Business Media.doi: 10.1007/978-3-642-35164-8.

Pfeffer, J. (1997). New directions for organization theory: Problems and prospects. Oxford University Press on Demand. doi: 10.1017/CBO9781107415324.004.

Popadic, M., Pucko, D., \& Cerne, M. (2016). Exploratory innovation, exploitative innovation and innovation performance: The moderating role of alliance partner diversity / research innovation, applied innovation and innovation efficiency: The role of moderating related diverse partners. Economic and Business Review for Central and SouthEastern Europe, 18 (3), 293. doi: 10.15458 / 85451.26.

Prajogo, D. I. (2016). The strategic fit between innovation strategies and business environment in delivering business performance. International journal of production Economics, 171, 241-249. doi: 10.1016/j.ijpe.2015.07.037.

Rangus, K., \& Slavec, A. (2017). The interplay of decentralization, employee involvement and absorptive capacity on firms' innovation and business performance. Technological Forecasting and Social Change, 120, 195-203.doi: 10.1016/j.techfore.2016.12.017.

Roberts, N. (2015). Absorptive capacity, organizational antecedents, and environmental dynamism. Journal of Business Research, 68(11), 2426-2433. doi: 10.1016/j.jbusres.2015.02.019.

Robbins, S. P. (1990). Organization Theory: Structures, Designs, And Applications, 3/e. Pearson Education India. Srivastava, R., \& Gautam, V. (2009). Organizational Effectiveness: Literature Review and a Research Framework for Food Processing $\quad$ Enterprises. Metamorphosis, 24. http://journals.sagepub.com.ezaccess.library.uitm.edu.my/doi/pdf/10.1177/0972622520090103.

Sayilar, Y. (2016) 'The Past, Present And Future Of Structural Contingency Theory', 'İŞ, GÜÇ' Industrial Relations and Human Resources Journal, 18 (October 2016), pp. 95-124 doi: 10.4026/2148-9874.2016.0333.X.

Schwab, D. P. (2013). Research methods for organizational studies. Psychology Press.https://doi.org/10.4324/9781410611284

Shih, W. L., \& Tsai, C. Y. (2016). The effects of knowledge management capabilities on perceived school effectiveness in career and technical education. Journal of Knowledge Management. doi: 10.1108/JHOM-09-2016-0165.

Simsek, Z. (2009). Organizational ambidexterity: Towards a multilevel understanding. Journal of management studies, 46(4), 597-624.doi: 10.1016/j.respol.2009.03.005.

Sinha, S. (2016). Managing an ambidextrous organization: balancing innovation and efficiency. Strategic Direction.doi: 10.1108/SD-05-2016-0061.

Smith, S. M. (2017). Organizational Ambidexterity: Welcome to paradox city. Human Resource Management International Digest. doi: 10.1108/HRMID-06-2016-0087.

Suzuki, O. (2015). Unpacking performance benefits of innovation ambidexterity: Evidence from the pharmaceutical industry. management revue, 328-348.doi: 10.1688/mrev-2015-04-Suzuki.

Trautmann, G. (2008). Global sourcing: An analysis of the Implications for Organization Design. Springer-Verlag.doi: 10.1007/978-3-8350-5434-9.

Tushman, M. L., \& O'Reilly III, C. A. (1996). Ambidextrous organizations: Managing evolutionary and revolutionary change. California management review, 38(4), 8-29. doi: 10.2307/41165852.

Volberda, H. W., van der Weerdt, N., Verwaal, E., Stienstra, M., \& Verdu, A. J. (2012). Contingency fit, institutional fit, and firm performance: A metafit approach to organization-environment relationships. Organization Science, 23(4), 1040-1054. doi: 10.1287/orsc.1110.0687. 
Vrontis, D., Thrassou, A., Santoro, G., \& Papa, A. (2017). Ambidexterity, external knowledge and performance in knowledge-intensive firms. The Journal of Technology Transfer, 42(2), 374-388.doi: 10.1007/s10961-016-9502-7. Zack, M. H. (Ed.). (2009). Knowledge and strategy. Routledge.

Zang, J., \& Li, Y. (2017). Technology capabilities, marketing capabilities and innovation ambidexterity. Technology Analysis \& Strategic Management, 29(1), 23-37.doi: 10.1080/09537325.2016.1194972. 